\title{
L-asparaginases from fungi: a mini review
}

Keywords: L-asparaginase; Aspartic acid; Ammonia; Acrylamide; Antitumor activity; Acute Lymphoblastic Leukemia

\section{Introduction}

L-asparaginase (L-asparagine amidohydrolase, 3.5.1.1) (LA) is an enzyme that catalyzes L-asparagine into aspartic acid and ammonia. For last few decades LA has received much attention due to its applications in the fields like medicine, pharmaceuticals as well as food industry. The antineoplastic properties of LA has made it the enzyme studied widely worldwide. ${ }^{1,2}$ Looking to the food industry application, LA reduces the formation of acrylamide in the fried and baked food and hence, reduces the risk of carcinogenicity. ${ }^{3,4}$

Antitumor activity of LA has been harnessed for effective treatment of acute lymphoblastic leukemia (ALL) for last 30years. Clinically useful LA has been available from Escherichia coli and Erwinia chrysenthemi ${ }^{1,5}$ Treatment of patients with LA of bacterial origin has been facing certain issues like development of allergic reactions and immunogenic complications. Besides, quick clearance from plasma and requirement for multiple administrations make the treatment very costly. These limitations call for searching for newer sources of LA.

Apart from bacteria, fungi are also potential sources for LA. Filamentous fungi as well as yeasts produce LA. However, L-asparaginase production by fungi is comparatively less studied. ${ }^{6,7}$ Harnessing fungi for LA could be more promising as compared to bacteria mainly because of two reasons (i) Less chance of immunological reactions as fungi are more closely related to human beings and (ii) extracellular production of LA leading of ease in purifying and reducing production cost. ${ }^{1,8}$

Fungi from terrestrial habitats as well as endophytic fungi have been studied for LA production. Rani et al., ${ }^{9}$ examined 38 soil fungi and observed 23 fungi to exhibit LA activities. Upon screening 364 tropical soil fungi, Meghavarnam \& Janakiraman ${ }^{10}$ recorded 135 to be LA positive. Nagarajan et al., ${ }^{11}$ recorded 31 out of 33 endophytic fungi to be LA positive. Thirunavukkarasu et al., ${ }^{7}$ examined endophytic fungi isolated from seaweeds occurring along the southern coast of Tamilnadu, southern India and screened for LA production. They observed 64 out of 82 isolates to be LA positive.

Fungi from marine habitats have also been examined and found to be promising candidates for LA production. Vala \& Dave ${ }^{2}$ reported marine-derived fungi to be rich source for LA. They observed that 14 out of 20 marine-derived fungal isolates produced LA. Farag et al., ${ }^{12}$ isolated 21 fungi from Red Sea coasts, Egypt and observed 5 of them to produced LA. They carried out enzyme immobilization study and confirmed the advantage of immobilization of the whole cells and reuse of them to increase the production of the enzyme.

Mohankumar \& Manonmani $^{13}$ examined 1-asparaginase from Cladosporium sp. grown on wheat bran by SSF, and observed $96 \%$ inhibition in acrylamide formation in potato chips. Huang et al., ${ }^{14}$ reported cloning and expression of Rhizomucor miehei L-asparaginase (RmAsnase) gene in Escherichia coli. The authors observed that RmAsnase possesses a remarkable potential for its application in the food industry as well as in chemotherapeutics for leukemia.
Volume 3 Issue I - 2016

Anjana KVala, Bharti P Dave

Department of Life Sciences, Maharaja Krishnakumarsinhji Bhavnagar University, India

Correspondence: Bharti P Dave, Department of Life Sciences, Maharaja Krishnakumarsinhji Bhavnagar University, Bhavnagar -36400I, India, Email anjana_vala@yahoo.co.in

Received: August 27, 2016 | Published: November II, 2016

Though, fungal LA like bacterial LA, have been reported to have antileukemic potentials, they have not so far been used commercially. Food industry has already harnessed LA from fungi, e.g. LA from Aspergillus niger and A. oryzae..$^{1,15}$

There has been a growing interest in the LA production using fungi and studies related to optimization and purification of LA are being reported, however, structural aspects of fungal LA are less explored compared to bacteria. Explorations on fungal LA may lead to enzyme with novel properties.

\section{Acknowledgements}

Thanks are due to the Department of Science and Technology, Government of India, New Delhi for financial support sanctioned under Women Scientist's Scheme (WOS-A) to AKV (SR/WOS-A/ LS-307/2013(G)).

\section{Conflict of interest}

The author declares no conflict of interest.

\section{References}

1. Batool T, Makky EA, Jalal M, et al. A Comprehensive review on L-Asparaginase and its applications. Appl Biochem Biotechnol. 2016;178(5):900-923.

2. Vala AK, Dave BP. Explorations on marine-derived fungi for LAsparaginase - Enzyme with anticancer potentials. Curr Chem Biol. 2015;9(1):66-69.

3. Kornbrust BA, et al. Asparaginase-an enzyme for acrylamide reduction in food products. In: Whitehurst RJ, Oort MV, editors. Enzymes in food technology. 2nd ed. USA: Wiley-Blackwell; 2009. p. 59-87.

4. Zuo S, Zhang T, Jiang B, et al. Reduction of acrylamide level through blanching with treatment by an extremely thermostable L-asparaginase during French fries processing. Extremophiles. 2015;19(4):841-851.

5. Borek D, Jaskólski M. Sequence analysis of enzymes with asparaginase activity. Acta Biochimica Polonica. 2001;484(4):893-902.

6. Lapmak K, Lumyong S, Thongkuntha S, et al. L-asparaginase production by Bipolaris sp. BR438 isolated from brown rice in Thailand. Chiang Mai J Sci. 2010;37(1):160-164.

7. Thirunavukkarasu N, Suryanarayanan TS, Murali TS, et al. Lasparaginase from marine derived fungal endophytes of seaweeds. Mycosphere. 2011;2(2):147-155. 
8. Shrivastava A, Khan AA, Shrivastav A, et al. Kinetic studies of Lasparaginase from Penicillium digitatum. Biochem Biotechnol. 2012;42(6):574-581.

9. Rani SA, Sundaram L, Vasantha PB. Isolation and screening of Lasparaginase producing fungi from soil samples. Int J Pharm Pharm Sci. 2012;4(1):279-282.

10. Meghavarnam AK, Janakiraman S. A simple and efficient dye-based technique for rapid screening of fungi for 1-asparaginase production. $J$ Exptl Biol Agricult Sci. 2015;3(2):123-130.

11. Nagarajan A, Thirunavukkarasu N, Suryanarayanan TS, et al. Screening and isolation of novel glutaminase free L-asparaginase from fungal endophytes. Res J Microbiol. 2014;9:163-176.
12. Farag AM, Hassan SW, Beltagy EA, et al. Optimization of production of anti-tumor 1-asparaginase by free and immobilized marine Aspergillus terreus. The Egyptian J Aq Res. 2015;41(4):295-302.

13. Mohan Kumar NS, Manonmani HK. Purification, characterization and kinetic properties of extracellular 1-asparaginase produced by Cladosporium sp. World J Microbiol Biotechnol. 2013;29(4):577-587.

14. Huang L, Liu Y, Sun Y, et al. Biochemical characterization of a novel 1 -aspar aginase with low glutaminase activity from Rhizomucor miehei and its application in food safety and leukemia treatment. Appl Environ Microbiol. 2014;80(5):1561-1569.

15. Morales F, Capuano E, Fogliano V. Mitigation strategies to reduce acrylamide formation in fried potato products. Annals of the New York Academy of Sciences. 2008;1126:89-100. 